\title{
Comparative analysis of MCDM methods for the assessment of sustainable housing affordability
}

\author{
Emma Mulliner ${ }^{1}$, NaglisMalys ${ }^{2,3}$ and Vida Maliene ${ }^{1,4,{ }^{*}}$
}

${ }^{1}$ School of the Built Environment, Liverpool John Moores University, Cherie Booth, Byrom Street, Liverpool L3 3AF, United Kingdom

${ }^{2}$ Faculty of Life Sciences and Manchester Centre for Integrative Systems Biology, Manchester Institute of Biotechnology, The University of Manchester, 131 Princess Street, Manchester M1 7DN, United Kingdom

${ }^{3}$ School of Life Sciences, The University of Warwick, Gibbet Hill Campus, Coventry, CV4 7AL, United Kingdom

${ }^{4}$ Institute of Land Management and Geomatics, Faculty of Water and Land Management, Aleksandras Stulginskis University, Universiteto 10, Akademija, Kaunas LT-53361, Lithuania

*-Corresponding author 


\begin{abstract}
While affordability is traditionally assessed in economic terms, this paper tests a new assessment method that draws closer links with sustainability by considering economic, social and environmental criteria that impact on a household's quality of life. The paper presents an empirical application and comparison of six different multiple criteria decision making (MCDM) approaches for the purpose of assessing sustainable housing affordability.

The comparative performance of the weighted product model (WPM), the weighted sum model (WSM), the revised AHP, TOPSIS and COPRAS, is investigated. The purpose of the comparative analysis is to determine how different MCDM methods compare when used for a sustainable housing affordability assessment model. 20 evaluative criteria and 10 alternative areas in Liverpool, England, were considered. The applicability of different MCDM methods for the focused decision problem was investigated. The paper discusses the similarities in MCDM methods, evaluates their robustness and contrasts the resulting rankings.
\end{abstract}

Keywords: WPM, WSM, AHP, TOPSIS, COPRAS, decision making, housing affordability, multiple criteria, MCDM, sensitivity analysis, sustainability 


\section{Introduction}

It is imperative that both affordability and sustainability issues are simultaneously tackled in order to create successful housing and communities. Affordable housing alone is not enough to achieve community and family wellbeing; households need decent quality affordable housing that is well located within good quality environments that are clean, safe and have good access to jobs, key services and public transport [1-3]. There is both an efficiency and equity imperative to ensure that affordable housing is environmentally sustainable and socially equitable [4]. Accordingly, it may not only be the cost of housing that needs to be addressed in order to improve housing affordability; access to amenities, facilities and the energy efficiency of housing may need to be improved to create successful and sustainable living environments $[5,6]$;. However, traditional measures of affordability are one dimensional and continue to focus solely on economic criteria as the basis of assessment [7-10].

Researchers suggest that the traditional way of defining and measuring housing affordability - the relationship between household's income and expenditure - is too limited [11-13]. Accordingly, in order to assist in achieve successful housing outcomes, there is a need to develop a more holistic housing affordability assessment tool that is better aligned with sustainability concerns and household wellbeing.

Limitations in the assessment of affordability can be eliminated by the use of methods which are able to take into account a wider range of criteria than traditional methods do. The paper aims to test a housing affordability assessment methodology that is more holistic and capable of considering such a broad spectrum of criteria that affect the wellbeing of households - including economic, environmental and social aspects. Here, a number of universally used MCDM methods - the Weighted Sum Model (WSM), the Weighted Product Model (WPM), the revised Analytic Hierarchy Process (AHP), Technique for Order of Preference by Similarity to Ideal Solution (TOPSIS), Complex Proportional Assessment (COPRAS) - applied for the assessment of sustainable housing affordability. Alternative's ranking results and tolerances to the change in criterion weight are compared amongst selected MCDM methods. The 
comparative analysis of these different methods will aid in establishing most appropriate and compatible methodology for the purpose of sustainable housing affordability assessment.

\section{Housing affordability}

The affordability of housing has received considerable attention across the globe for a number of years [13-20]. However, the concept and measurement of housing affordability remains a challenging and contested issue. Affordability measures generally focus on the financial burden of housing costs, such as the house price to income ratio approach [20] , the residual measure (income remaining after housing costs) [21] and, since the impact of the latest recession, purchase and repayment affordability measures [7]. The most commonly referred to and internationally recognised method of measuring affordability is the ratio method, which determines the proportion of income spent on housing costs [10]. This is not surprising since it has the advantage of being easy to compute as it only relies on a few, usually easily accessible, variables. Nevertheless, this simplicity is precisely what limits its effectiveness since it does not incorporate a number of factors that affect housing affordability and the household situation. This traditional approach is one-dimensional and researchers [5,11-13,22-24] are increasingly documenting its limitations. In particular, the ratio measure fails to account for differences in housing costs that are the result of perceived higher neighbourhood quality [23]. Belsky et al. [22] suggest that an ideal affordability appraisal would account for the trade-offs that households make to lower housing costs, such as transportation, access to public services, health and safety. Stone et al. [25] also emphasise a growing concern that standard affordability measures do not recognise the trade-offs between cheap or affordable housing; just because a household has an 'affordable dwelling' does not necessarily mean it has 'affordable living', owing to trade-offs. Likewise, Rowley and Ong [13] recognise that, in reality, housing affordability encompasses quality and location trade-offs. Additional costs may be imposed on households as a result of such trade-offs, both monetary and socioeconomic costs, which are disguised by traditional measures of affordability. 
Housing affordability is a complex and multi-dimensional issue. Accordingly, to gain a better insight into the problem, it should not be analysed using just one concept, measure or definition [26,27]. It is clearly difficult, perhaps impossible, to address all concerns related to affordability within one simple measure. Issues such as housing adequacy, e.g. physical quality, location and access to services and appropriateness may need to be addressed by additional complementary indicators [12]. McCord et al. [27] elucidate that a one measure fits all approach to assessing affordability is problematic and policy makers must consider more than one measure when reforming policy instruments. Despite these findings, research often continue to focus on economic criteria alone as the basis of housing affordability assessments [7-10], with little regard for what households get in return for what they spend on housing in terms of housing location and neighbourhood characteristics. There is a specified need for the criteria by which housing is judged as affordable to be refined [11].

The literature highlights the need for innovations in the assessment of housing affordability. The researchers postulate that housing affordability must be defined and assessed in a more meaningful way, requiring a new paradigm of thinking that goes beyond the financial implications experienced by households. An international desire to create more affordable and more sustainable communities means that closer links must be drawn between economic, environmental and social concerns. Housing affordability and sustainability issues are increasingly being discussed mutually and are recognised as being interlinked. Affordable housing clearly has a fundamental role to play in contributing to the improved economic, environmental, social and physical health of communities $[28,29]$. While at the same time, a sustainable living environment has an essential role to play in contributing to the success of affordable housing $[2,3]$. It is therefore important that such issues are tackled simultaneously. Accordingly a broader range of criteria ought to be considered in relation to housing affordability in order to create successful housing and communities for society to reside in [30]). Limitations in the assessment of affordability can be eliminated by the use of methods which are able to take into account a wider range of criteria than traditional methods do. 
Methods such as cost benefit analysis (CBA) and hedonic modelling were considered for this purpose. CBA seeks to quantify the benefits and costs associated with a particular alternative. However, critics claim that CBA is of limited use in complex situations because all criteria must be measured in monetary terms [31]. A monetary value cannot be assigned to all factors related to housing affordability, such as social and environmental considerations, including individuals' welfare.Hedonic modelling is based on the fact that prices of goods in a market are affected by their characteristics. This helps to estimate the value of a commodity based on people's willingness to pay for the commodity as and when its characteristics change. However, if consumers are unaware of the relationship between certain characteristics and the benefits they may have on them or their housing, then the value will not be reflected in the property price. Once more, this method focuses on obtaining economic values for characteristics and this may be difficult to ascertain for some environmental and social factors. Moreover, the amount of data that needs to be collected for hedonic modelling is extremely large. Given the presence of numerous conflicting factors, multiple criteria decision making (MCDM) methods were deemed particularly suitable for this issue and are utilised as the basis of the sustainable housing affordability assessment.

\section{Overview of multiple criteria decision making methods}

MCDM is a set of methods which deal with the evaluation of a set of alternatives in terms of numerous, often conflicting, decision criteria [32,33]. Thus, given a set of alternatives (options) and a number of decision criteria, the goal of MCDM is to provide a choice, ranking, description, classification, sorting and in a majority of cases an order of alternatives, from the most preferred to the least preferred option [34-36]. There are three stages that all MCDM techniques follow [32]:

1. Determine relevant criteria and alternatives;

2. Attach numerical measures to the relative importance of the criteria and to the impacts of the alternative on these criteria; 
3. Process the numerical values to determine a ranking of each alternative.

MCDM can consider qualitative and quantitative criteria. While criteria based on quantitative variables are expert independent, qualitative criteria (variables) are expert dependent and may be subjective, since different approaches such as ranking, point or other systems can be used to transform qualitative variable into quantitative units compatible with MCDM methodology. Thus, in decision making, qualitative variables (criteria) are transformed into quantitative variables using expert-designed indicators and units.

This paper is concerned with the processing of the numerical values in the final decision matrix and the determination of the ranking of the alternatives; i.e. the weights of the decision criteria and the performance of the alternatives in terms of each criterion are predetermined by the expert method.

The literature presents an array of MCDM methodologies, each with their own characteristics, varying levels of sophistication and diverse scope of application [37-44]. There are different classifications of MCDM problems and methods. MCDM problems are frequently categorised according to the nature of the alternatives; either discrete or continuous [33,45-47]. A discrete problem can be described as a multi attribute discrete option, which often consists of a modest collection of alternatives (Multi Attribute Decision Making (MADM)), whereas a continuous problem usually consists of a vast or infinite amount of decision alternatives (Multi Objective Decision Making (MODM)) [33,45]. MCDM methods may also be classified depending on their compensatory or non-compensatory nature. Compensatory methods allow explicit tradeoffs among criteria, whereas non-compensatory methods are principally based on the comparison of alternatives with respect to individual criteria. The objective of this study is to assess different housing locations based on an established set of sustainable housing affordability assessment criteria. The decision making situation is thus a ranking problem where alternatives need to be ranked from best to worst. The problem has a discrete nature, that is to say the alternatives (housing locations) will be pre-specified, and therefore a MADM method will be suitable in this instance. Consequently, the paper focuses on MADM methods. 
For MADM problems there are generally two Schools of thought; those based on multi-attribute value functions and multi-attribute utility theory (MAUT) (the American School) [48] and those based on outranking methods (the French School) [49]. The methods based on MAUT commonly have a compensatory nature and mainly consist of aggregating the criteria into a function which has to be maximised [36] In contrast, the outranking methods allow for incomparability between alternatives. ELECTRE [49] and PROMETHEE [50] are the most widely used outranking methods. However, it has been suggested that ELECTRE and PROMETHEE are not always able to give a complete ranking of the alternatives [32,50,51] . Accordingly, such methods may be unsuitable for the type of decision problem in hand and have not therefore been considered in this study.

\section{Multiple criteria assessment of sustainable housing affordability}

Numerous MCDM methods have been applied in housing and sustainability studies. For example, AHP has been used to aid house selection for buyers [52], to analyse the environmental preferences of homeowners [53], to examine housing location attributes [54] and in the assessment of urban quality of life in Iran [55]. COPRAS has been used to determine the most rational housing investment instruments and lenders in Lithuania [56], to evaluate the sustainability of residential areas [57] and to define the utility and market value of real estate [58]. PROMETHEE has been used to assess land-use suitability for residential housing construction [59]. The WSM, WPM, AHP, revised AHP, TOPSIS and COPRAS have aided in the process of building maintenance [60]. SAW, TOPSIS and ELECTRE were utilised to assist

stakeholders in making better decisions on housing evaluation [61]. Furthermore, COPRAS, SAW and multiplicative exponential weighting (MEW) were applied for the purpose of selecting an appropriate dwelling, taking into account the environmental impact of its construction, financial and qualitative criteria [62].

MCDM methods have become increasingly popular in decision-making for sustainability given the multi-dimensionality of the concept [51]. MCDM methods are suitable for the 
evaluation presented in this paper since affordability and sustainability issues aremultidimensional and involve multiple conflicting criteria. MCDM methods can incorporate these various aspectsinto one evaluation process; MCDM is capable of considering criteria of incommensurable units of measure (e.g. ratios, points, percentages) and those of both benefit (positive) and cost (negative) influence.

The initial data collection process (in this case) for the basis of the MCDM methods includes the following stages:

- determine criteria for the comprehensive assessment of sustainable housing affordability (achieved via literature review and interviews with professionals);

- determine criteria weights to reflect their importance (achieved via questionnaires surveys conducted with professionals);

- $\quad$ select decision alternatives for comparison;

- $\quad$ calculate criteria values for each alternative (see measurement examples in Mulliner and Maliene [63]).

A total of 20 decision criteria were identified for the basis of the sustainable housing affordability assessment and weights wereintroduced in order to express the relative importance of the criteria (table 1). The criteria were identified via interviews with housing and planning professionals in the UK and a supplementary extensive literature review [63]. A questionnaire survey was distributed to housing and planning professionals across all regions of the UK in order to further verify the criteria and elicit data on the importance of the criteria.Over 300 experts from different regions of the UK ranked the criteria on a scale of importance ranging from 1 to 10, where a ranking of 1 meant "not important" and a ranking of 10 meant "most important". In order to calculate criteria weights, the mean ranking of importance obtained for each criterion was divided by the sum of the mean scores, as such it ensures the total of all weights is equal to one.

Liverpool, UK, was chosen as the location for the empirical case study. Although it has experienced relatively fast economic grow in recent decade, this city still contains some of the 
most deprived areas (housing wards) in the UK and thus is an excellent example for this type of study. However, the MCDM methodology could be applied to any city or region within the UK or potentially worldwide.

Ten housing wards in Liverpool were randomly selected for comparison purposes. The alternatives were: $A_{1}$ (Everton), $A_{2}$ (Childwall), $A_{3}$ (West Derby), $A_{4}$ (Cressington), $A_{5}$ (Allerton and Hunts Cross), $A_{6}$ (Yew Tree), $A_{7}$ (Belle Vale), $A_{8}$ (Princes Park), $A_{9}$ (Fazakerley) and $A_{10}$ (St Michaels) (Figure 1). The alternative areas were each measured against the 20 decision criteria and the values obtained are shown in table 1 . Succeeding the initial data collection, a variety of MCDM methods can be applied to the data in order to process the values and prioritise the alternative areas.

\section{$<$ Figure 1 here $>$}

\section{Comparative analysis of MCDM methods}

Despite the large quantity of MCDM methods available, no single method is considered the most suitable for all types of decision-making situation $[64,65]$. This generates the paradox that the selection of an appropriate method for a given problem leads to an MCDM problem itself [32]. A major criticism of MCDM is the reality that different methods can yield different results when applied to the same problem [36]. The identification and selection of an appropriate MCDM method is thus not a simple task and considerable consideration must be given to the choice of method. The literature presents a number of practical applications comparative analyses of different MCDM methods [47, 66-68]. Furthermore, a number of authors have developed guidelines facilitating the choice of an appropriate MCDM method [64, 65]. However, it has also been acknowledged that several methods can be potentially valid for a particular decision making situation; there is not always an overwhelming reason to adopt one technique over 
another [69].It seems that one of the most important criteria in selecting a MCDM method is its compatibility with the problem's objective [49].

The problem proposed in this study is to assess the sustainable housing affordability of a number of alternative areas. To achieve this, a ranking of alternatives needs to be identified. Therefore, the objective of this problem is to rank alternatives. Consequently, a MCDM method that has the ability to provide a complete ranking of alternatives (indicating the position of each alternative) is required. Additionally, the method must have the ability to handle both benefit and cost criteria and those of a quantitative and qualitative nature. Furthermore, ease of use and understanding of the MCDM technique is important so that any interested parties can easily adopt the proposed method.

The comparative performance of several appropriate MCDM methods - the WSM, WPM, the revised AHP, TOPSIS and COPRAS - is investigated in this paper. These techniques are applied to the practical case study data contained in the initial decision making matrix (Table 1). Using each method, the aim is to determine the relative significance of each alternative under assessment, as well as establishing the priority order of the alternatives in respect of one another. The selected methods for the comparative analysis differ in their basic principles, the type of data normalization process and the way they combine the criteria values and the criteria weights into the evaluation procedure. Since criteria generally have different units of measurement, MCDM methods use a form of normalization to eliminate the units of criterion values (e.g. ratio, points, percentage, price) so that all the criteria are non-dimensional [36]. There are different techniques of normalization but in many cases this stage is essential to the consistent and correct application of the method. The WSM, WPM, revised AHP and COPRAS methods are fairly similar in their normalisation procedure, although TOPSIS is somewhat different. 


\subsection{Weighted Sum Model (WSM)}

The WSM (also known as simple additive weighting (SAW) method) [70] is one of the simplest and most commonly used MCDM methods. The method involves adding together criteria values for each alternative and applying the individual criteria weights. Generally, the WSM only deals with benefit criteria. Accordingly, it was necessary for cost (minimizing) criteria to be transformed into benefit (maximizing) ones prior to normalization. The transformation of cost criteria into benefit ones can be achieved by a simple process (Hwang and Yoon 1981):

$$
\hat{r}_{i j}=\frac{\min _{j} r_{i j}}{r_{i j}}(i=1, \ldots, m ; j=1, \ldots, n)
$$

Succeeding such a transformation, the lowest criterion value becomes the largest and the largest value becomes the lowest. Following this transformation on cost criteria, a new initial matrix was created using only benefit values (Table 2). The normalized matrix can then be created by dividing each criterion value by the sum of its row. Then each criterion value is multiplied by its corresponding weight. Once values for all alternatives have been aggregated, the alternative with the highest value is selected as the best solution [70]:

$$
A_{W S M}^{*}=\max _{j} \sum_{i=1}^{M} w_{i} a_{i j}
$$

Here the $M \times N$ matrix $A$ has data entries $a_{i j}$ corresponding to the value of the $j$ th (of $N$ ) alternatives in terms of the $i$ th (of $M$ ) decision criterion. $A^{*}$ is the WSM score of the optimal alternative and $w_{i}$ is the weight (importance) of the $i$ th criterion. 


\subsection{Weighted Product Model (WPM)}

The WPM $[71,72]$ is akin to the simple WSM method. The principal difference is that in the main mathematical process there is multiplication instead of addition, where each alternative is compared with the others by multiplying a number of ratios, one for each criterion and each ratio is raised to the power equivalent of the relative weight of the corresponding criterion. [73]. Like for use of the WSM, the WPM also requires cost criteria to be transformed into benefit ones prior to normalization. From the normalised matrix, we calculate [71,72]:

$$
A^{*}=\max _{j} \prod_{i=1}^{M} a_{i j}^{w_{j}}
$$

$A^{*}$ is the WPM score of the optimal alternative.

\subsection{The revised Analytic Hierarchy Process (revised AHP)}

The AHP is based on the use of pair-wise comparisons, both to estimate criteria weights and to compare the alternatives with regard to the decision criteria [74]. If criteria values and weights cannot be obtained directly then a method based on the pair-wise comparisons must be employed. In this instance, criteria weights were pre-determined by the expert method and not using AHP. Only the final stages of the AHP, i.e. the processing of the numerical values, were required in this study. The final step in the AHP deals with the construction of an $M \times N$ matrix (where $M$ is the number of alternatives and $N$ is the number of criteria) that is made using the relative importance of the alternatives in terms of each criterion [32]. Although this is similar to WSM, a central difference with the AHP method is that the values of the decision matrix are normalized to sum to 1 . Belton and Gear [75] observed a problem with the original AHP method; they noted that AHP can reverse the ranking of the alternatives when an alternative identical to one already existing is introduced. Accordingly, they proposed a revised version where, instead of having the relative values of the alternatives sum up to one, each relative value is divided by the maximum value of the relative values $[32,75]$. This revision was subsequently accepted as a variation of the original AHP and is also referred to as 'ideal mode AHP' [76]. Triantaphyllou and 
Mann [73] advocate that the revised version appears to be more powerful than the original AHP approach.

The revised AHP method was tested in two different ways:

1. Revised AHP 1 - The first approach uses only benefit criteria values within the assessment. Thus, as with the WSM and WPM, cost criteria were transformed into benefit ones prior to normalization of the matrix (table 2). This is the standard way of handling cost criteria with the AHP methods [77].

2. Revised AHP 2 - The second approach uses both benefit and cost criteria values. Cost criteria were kept within the analysis by incorporating them as negative weights within the initial matrix. In order to do so, weights for cost criteria were multiplied by -1 .

The remaining stages of the revised AHP process were the same for both approaches. The normalisation procedure of the revised AHP involves dividing each relative criterion value by the maximum value of the relative values. Subsequently, each normalised value is multiplied by its weight. Then, the sum of all the weighted normalised criteria values for each alternative is computed to obtain a final score for the alternative. The best alternative (when all the criteria are maximizing) is indicated by the following additive formula:

$$
A_{A H P}^{*}=\max _{i} \sum_{j=1}^{N} q_{i j} w_{j,} \text { for } i=1,2,3, \ldots, M .
$$

\subsection{COPRAS (Complex Proportional Assessment)}

COPRAS [78] acts in a similar way to the WSM. However, COPRAS allows for both benefit and cost criteria to be considered within the matrix and the data are normalized so that different measurement units can be used and compared.

The procedure of the COPRAS method is generally carried out in the following stages [56]. The first step is the normalisation of the decision-making matrix: 


$$
d_{i j}=\frac{q_{i}}{\sum_{j=1}^{n} x_{i j}} \cdot x_{i j}
$$

Where $x_{i j}$ is the value of the $i$-th criterion of the $j$-th alternative, and $q_{i}$ is the weight of the $i$-th criterion.

The second stage calculates the sums of weighted normalised criteria describing the $j$-th alternative. The alternatives are described by benefit (maximising) criteria $S_{+j}$ and cost (minimising) criteria $S_{-j .}$ Sums are calculated according to the formulae:

$$
\begin{aligned}
& S_{+j}=\sum_{z_{i}=+} d_{i j} \\
& S_{-j}=\sum_{z_{i}=-} d_{i j}
\end{aligned}
$$

The significance of the comparative alternatives is determined in the third stage on the basis of describing benefit $(+)$ and cost $(-)$ qualities that characterise the alternatives. The relative significance $Q_{j}$ of each alternative $A_{j}$ is determined according to:

$$
Q_{j}=S_{+j}+\frac{S_{-\min } \cdot \sum_{j=1}^{n} S_{-j}}{S_{-j} \cdot \sum_{j=1}^{n} \frac{S_{-\min }}{S_{-j}}}, j=\overline{1, n}
$$

The first term of $Q_{j}$ increases for higher positive criteria $S^{+}$, whilst the second term of $Q_{j}$ increases with lower negative criteria $S_{j}$. The fourth stage is the prioritisation $Q_{j}$ of the alternatives. The greater the value $Q_{j}$, the higher the priority (significance) of the alternative. In this case, the significance $Q_{\max }$ of the most rational alternative will always be the highest. The method also estimates the utility degree of the alternatives, showing, as a percentage, the extent to which one alternative is better or worse than the others being compared [66]. With the increase/decrease of the priority of the analysed alternative, its degree of utility also 
increases/decreases. The degree of utility is determined by comparing each analysed alternative with the most efficient one. The optimal alternative is expressed by the highest degree of utility $N_{j}$ equalling $100 \%$. All utility values related to the considered alternatives will range from $0 \%$ to $100 \%$, between the worst and best alternative out of those under consideration. The degree of utility $N_{j}$ of the alternative $A_{j}$ is determined according to the following formula:

$$
N_{j}=\frac{Q_{j}}{Q_{\max }} \cdot 100 \%
$$

Where $Q_{j}$ and $Q_{\max }$ are significances of the alternatives calculated at the previous stage.

\subsection{TOPSIS}

TOPSIS is based on an aggregating function representing closeness to reference points [45]. TOPSIS approaches a MCDM problem by considering that the optimal alternative should have the shortest distance from the ideal solution and the farthest distance from the negative-ideal solution TOPSIS can be applied both to maximizing (benefit) and minimizing (cost) criteria [78]. TOPSIS begins with the normalization of criteria values, using vector normalisation. The normalized value $r_{i j}$ is calculated as [32]:

$$
r_{i j}=\frac{x_{i j}}{\sqrt{\sum_{i=1}^{M} x_{i j}^{2}}}
$$

Where $x_{i j}$ represents the value of $j$-attribute for $i$-alternative, $r_{i j}$ represents the value of the new normalized decision-making matrix.

The next step is to calculate the weighted normalized decision matrix V. A set of weights $W=\left(w_{1}, w_{2}, \ldots, w_{n}\right)$ with $\sum w_{i}=1$ is used in combination with the previous normalised decision matrix to determine the weighted normalized matrix $\mathrm{V}$, defined as: 


$$
v_{i j}=w_{i j} r_{i j}
$$

The ideal/best $\left(\mathrm{A}^{*}\right)$ solution and the negative-ideal/worst (A-) solution is then determined:

$$
\begin{aligned}
A^{*} & =\left\{\left(\operatorname{măx} v_{i j} \mid j \in J\right),\left(\min v_{i j} \mid j \in J\right) \mid i=1,2,3, \ldots, M\right\}= \\
& i \quad i \\
& =\left\{v_{1^{*}}, v_{2^{*}}, \ldots, v_{N^{*}}\right\} . \\
A^{-} & =\left\{\left(\min v_{i j} \mid j \in J\right),\left(\operatorname{man} v_{i j} \mid j \in J\right) \mid i=1,2,3, \ldots, M\right\}= \\
& i \quad i \\
& =\left\{v_{1^{-}}, v_{2^{-}}, \ldots, v_{N^{-}}\right\} .
\end{aligned}
$$

Where $J=\{j=1,2, \ldots, N$ and $j$ is associated with benefit criteria $\}$; and $J^{\prime}=\{j=1,2, \ldots, N$ and $j$ is associated with cost/loss criteria\}.

The ideal solution represents a hypothetical option that consists of the most desirable level of each criterion across the options under consideration. Whereas the negative-ideal solution represents a hypothetical option that consists of the least desirable level of each criterion across the options under consideration. The separation measure (distance) of each alternative from the ideal-solution and negative-ideal solution using the n-dimensional Euclidean distance method is then calculated:

$$
S_{i}^{*}=\sqrt{\sum_{j=1}^{n}\left(v_{i j}-v_{j}^{*}\right)^{2}}, i=1, \ldots, M .
$$

Where $S_{i^{*}}$ is the separation (in the Euclidean sense) of each alternative from the ideal solution.

$$
S_{i}^{-}=\sqrt{\sum_{j=1}^{n}\left(v_{i j}-v_{j}^{-}\right)^{2}}, i=1, \ldots, M
$$


Where $S_{i}$ is the separation (in the Euclidean sense) of each alternative from the negative-ideal solution.

The relative closeness of each alternative $A_{j}$ to the ideal solution $A^{*}$ can be calculated:

$$
C_{i^{*}}=\frac{S_{i^{-}}}{S_{i^{*}}+S_{i^{-}}}, 0 \leq C_{i^{*}} \leq 1, i=1,2,3, \ldots, M
$$

If $C_{i}=1$ then $a_{i}=A^{*}$ (ideal solution) and if $C_{i}=0$, then $a_{i}=A-$ (anti-ideal solution). Therefore, the conclusion is that the alternative $a_{i}$ is closer to $A^{*}$ if $C_{i}$ is closer to the value of 1 .

Finally, the preference order is ranked according to $C_{i}$. The best alternative will be the one that is closest to the ideal solution and the maximum distance away from the anti-ideal solution $[45,79]$. Thus, the optimal alternative should be the one that best maximises the beneficial criteria and minimises the unbeneficial criteria. However, while these two reference points (ideal and anti-ideal) are identified, TOPSIS does not consider the relative importance of the distances from such points [41]. The TOPSIS method uses squared terms in the evaluation of criteria and this should be highlighted. The consequence of this is that very good and very bad data points (criteria values) can be exaggerated, having more of an impact on the final outcome, whereas average data points will not have as much of an impact (in comparison with methods that do not utilise squared terms). Methods that utilise squared terms may be suitable particularly where criteria values for different alternatives are similar, thus requiring further distinguishing.

\section{Comparison of alternative rankings using different MCDM methods}

The MCDM methods (WSM, WPM, revised AHP (approach 1 and 2), TOPSIS and COPRAS) were applied to the case study data. TOPSIS, COPRAS and Revised AHP 2 were applied to the initial decision making matrix in table 1, while it was necessary for WSM, WPM and revised AHP 1 to be applied to the initial matrix containing only benefit values (Table 2). The obtained ranking results are presented in Table 3. The priority order of the alternatives is compared in Table 4; in 
order to easily identify and demonstrate where different methods have acted in the same way with regard to the prioritisation of alternatives, highlighting has been used. All tested methods concluded that the optimal alternative was $A_{10}$ (St Michaels). All methods ranked $A_{4}$ (Cressington) in $2^{\text {nd }}$ position. Three of the approaches, all except TOPSIS and WPM, concluded that $A_{7}$ (Belle Vale) was the worst performing alternative, followed by $A_{9}$ (Fazakerley), ranking $10^{\text {th }}$ and $9^{\text {th }}$ consecutively, whereas TOPSIS and WPM ranked $A_{7}$ (Belle Vale) as $9^{\text {th }}$ priority. Revised AHP acted rather similarly to WSM, with both methods ranking six of the alternatives $(60 \%)$ in identical positions. COPRAS also acted rather similarly to WSM, with both methods ranking five of the alternatives (50\%) in identical positions. TOPSIS acted most correspondingly to the revised AHP, with the two methods prioritising four of the alternatives (40\%) in identical positions. However, the two methods also produced some rather contrasting results, for example, in relation the prioritisation of $A_{2}$ (Childwall). In fact, $A_{2}$ produced rather unstable rankings by the different methods tested, along with $A_{1}$ and $A_{8}$. Although it is not usual to adopt the second approach within the revised AHP method, i.e. incorporating cost criteria as negative weights, the final priority order of the alternatives was actually equivalent using both approaches (table 3). Accordingly, this approach could be a valid option for future studies that wish to incorporate cost criteria within AHP methods. The WPM was the most inconsistent with the other methods tested, in terms of the prioritisation of alternatives. It should be noted that the use of the WPM proved problematic owing to the ' 0 ' (zero) value assigned to $C_{20} / A_{5}$ within the initial matrix (table 1)/ $C_{20} / A_{1}$ within the 'all benefit' criteria matrix (table 2). This method does not seem to function well where criterion values of zero are used and this may have contributed to the dissimilar rankings achieved by the method. 
The similarity in the rankings obtained by different methods can be further demonstrated by analysis of pairwise correlation. Pairwise correlation between the MCDM methods showed that five methods (COPRAS, TOPSIS, WSM, revised AHP 1 and 2) out of six methods perform very similarly (Pearson correlation coefficient of 0.831 to 0.995 ) with revised AHP1 and revised AHP2 methods delivering the same rankings of alternatives (Table 5). The overall similarity of one MCDM method to all other methods used in the analysis compared as follows (with average correlation coefficient shown in brackets): COPRAS (0.786) > TOPSIS $(0.762)>$ WSM $(0.745)>$ revised AHP1/2 $(0.735)>$ WPM $(0.266)$. COPRAS, WSM, revised AHP 1 and 2 highly correlated amongst themselves, which is not surprising as all four methods are principally nearly identical. Interestingly, TOPSIS method, which differs significantly from other MCDM methods on the basis that the optimal alternative should have the shortest distance from the ideal solution and the farthest distance from the negative-ideal solution, showed very high similarity to COPRAS (Pearson correlation coefficient of 0.969 ) and highly correlated with WSM, revised AHP 1 and 2 methods. These findings are fairly consistent with a number of other studies comparing the results obtained by applying several MCDM methods. For example, Banaitiene et al. [66] found that SAW (also known as WSM), TOPSIS and COPRAS produced equal rankings of alternatives. Ginevicius and Podvezko [80] also used SAW, TOPSIS and COPRAS and found similarity, albeit not entirely equal, in the ranking of alternatives. Rao [81] found similarity in the rankings given by TOPSIS, COPRAS and AHP. Zanakis et al. [47] concluded that all version of AHP behave similarly to SAW, while they found that TOPSIS behaves closer to AHP.

\section{Sensitivity analysis}


Ranking results in the MCDM depends heavily on the nature of criteria that are used in the analysis and most notably on a distribution of the weighting amongst criteria. Also, it has to be taken into consideration that the criteria weights are usually established on the basis of professional perception, which can be to some extent subjective and may vary accordingly. Therefore, effect of a possible deviation of the weight value should be evaluated.

The professional opinion-determined values of criteria weights and values of alternatives were combined in the mathematical models of MSDM methods described in subsections 5.1-5.5. A sensitivity analysis was performed to quantify the level of crosstalk between criteria and ranking, through revealing how ranking of alternatives change due to variation of criteria weights. Results of the sensitivity analysis for each individual criterion were compared in Figure 2.

\section{$<$ Figure 2 here $>$}

Table 6 and Figure 3 represent distribution of sensitivity coefficients. The specific value of the sensitivity coefficient means that a $5 \%$ or $50 \%$ increase or decrease of the criterion weight leads to a single, double or multiple changes in the ranking of alternatives. Results revealed that criteria $\mathrm{C} 3, \mathrm{C} 8, \mathrm{C} 12, \mathrm{C} 13, \mathrm{C} 15$ and $\mathrm{C} 19$ were robust for all six MCDM methods used in the analysis.

\section{$<$ Table 6 here>}

$<$ Figure 3 here $>$

The comparative analysis of the distribution of sensitivity coefficient revealed that the simulated 5\% change in criterion weight (increase and decrease) did not have any influence on ranking of alternatives by using WPM and COPRAS methods and had some effect on the ranking with other methods. The WPM method-based ranking was least effected by the $50 \%$ change in 
criterion weight, while other methods tolerated such change within acceptable limits for most of the criteria (Figure 2, Table 6).

Next, we investigated what is the most critical criterion in each MCDM model. The "most critical criterion" was defined as the criterion $C_{j}$ for which the smallest relative change (in percentage), denoted as $D_{j}$, in its weight value $W_{j}$ must occur to alter the existing ranking of the alternatives. The sensitivity coefficient of criterion $C_{j}$, denoted as $S C_{j}$, can be used as a measure of sensitivity to the change of criterion weight and is given as follows:

$$
S C_{j}=\frac{1}{D_{j}}, \quad j=\overline{1, n} .
$$

As shown in the Figure 4, criteria C4 (WSM), C20 (WPM, TOPSIS and COPRAS) and C16 (Revised AHP 1 and 2) were identified as most critical criteria for any alternative, and C16 was the most critical criterion for best alternative in case of all MCDM methods.

\section{$<$ Figure 4 here $>$}

\section{Discussion}

The decision making situation proposed in this study required the assessment of a number of alternative housing wards in respect of their sustainable housing affordability. Therefore, a ranking (prioritisation) of housing wards was one of the main objectives of the problem in question. Accordingly a method(s) with the ability to provide a complete ranking of alternatives, indicating the position of each alternative, were necessary. Additionally, the method(s) required the ability to handle criteria of both benefit and cost influence. Furthermore, it was important to make sure the technique(s) are easy to use and understand so that any interested parties can easily adopt the proposed method in practice. 
The comparative analysis of several MCDM methods - WSM, WPM, revised AHP (approach 1 and approach 2), TOPSIS and COPRAS - assisted in selecting a most appropriate method(s) for this study (sustainable housing affordability assessment). The testing of these methods highlighted that the WSM, revised AHP methods and COPRAS are relatively simple to use. The WPM also appeared straightforward, although it was problematic with the use of zero values within the analysis. However, a drawback of the WSM, WPM and revised AHP is that benefit and cost criteria should not generally be used at the same time within the analysis. Cost criteria ought to be transformed into benefit criteria prior to normalisation. However, Millet and Schoner [77] discussed this transformation in relation to the AHP methods and suggest that it can cause computational complexity and elicit inconsistent results. There is an option, mathematically, to incorporate cost criteria as negative weights within methods, as demonstrated within the comparative analysis with the revised AHP (approach 2). However, such a way of dealing with cost criteria is not generally adopted in practice and thus the results may not always be acceptable. In contrast, the TOPSIS and COPRAS methods allow for both benefit and cost criteria to be incorporated with one analysis without difficulty or question. However, the TOPSIS method was more complex and time consuming to apply in comparison to COPRAS. Dyer et al. [82] warn that the complexity of many MCDM methods can prevent their application in practice. Moreover, the findings of several comparative studies actually suggest that simpler evaluation techniques are often superior $[47,67,68]$.

After conducting the comparative analysis, the authors have established that it is important to use alternative MCDM methods in order to thoroughly evaluate sustainable housing affordability, since all methods produced somewhat different ranking results. The COPRAS, TOPSIS, WSM, revised AHP 1 and 2 methods showed most consistency amongst themselves. Although none of these five methods outclassed others considerably, the correlation analysis showed that COPRAS would be an optimal choice if one method to be used for alternative's ranking purpose. The sensitivity analysis also revealed that COPRAS (together with WPM) tolerated best the 5\% change in criterion weight (increase and decrease), which did 
not have any influence on ranking alternatives using these two methods. COPRAS has also the ability to account for both benefit (maximizing) and cost (minimizing) evaluation criteria, which can be assessed separately within one evaluation process. Contrastingly, the WSM and revised AHP methods require transformation of cost criteria into benefit ones. This makes the procedure more complicated and time consuming for potential users and can elicit inconsistent results. The COPRAS method is transparent, simple to use and has a low calculation time in comparison with other MCDM methods, such as the AHP and TOPSIS [83]. This was confirmed during the comparative analysis. Therefore, the COPRAS method can more easily be adopted by any interested parties in the future. An important feature that makes the COPRAS method superior to other available MCDM methods is that it estimates the utility degree of alternatives, showing, as a percentage, the extent to which one alternative is better or worse than other alternatives taken for comparison. Visually, this can further aid the decision maker and would be particularly useful for the presented sustainable housing affordability assessment method if results are utilised by, for example, policy makers and planners. Furthermore, recent research shows that decisions yielded by the COPRAS method are more efficient and less biased than those yielded by TOPSIS and SAW (also known as WSM) [84].

Finally, sensitivity analysis showed that if criterion weights are subjected to higher level of change (50\% increase or decrease), other MCDM methods such as TOPSIS, WSM and WPM should be considered as their tolerance to criterion change in some instances can outperform COPRAS method. In particular, WPM method showed exceptional tolerance to the high level of uncertainty in criterion weight. This can be explained by the peculiarity of the mathematical process of this method, involving multiplication instead of addition in the course of alternative comparison.

\section{Conclusions}

In order to formulate a comprehensive and sustainable assessment of housing affordability multiple criteria, including economic, environmental and social aspects influencing households, 
should be considered. Owing to the numerous conflicting decision criteria present, MCDM methodologies were considered suitable for the housing affordability assessment. These evaluation methods allow the multidimensional character of the sustainable housing affordability decision criteria to be taken into account, as well as their varying levels of importance.20 weighted decision criteria were used in the assessment of sustainable housing affordability for 10 alternative areas (housing wards) within Liverpool, England as a case study.

Frequently, different MCDM methods can yield different results when applied to the same problem. Accordingly, in order to test the performance of potentially suitable methods, a comparative analysis of a number of MCDM approaches - WSM, WPM, revised AHP, TOPSIS and COPRAS - was undertaken. The comparative analysis of these different methodologies confirmed an earlier view that alternative MCDM methods need to be used for thorough and, most significantly, critical assessment fordecision making. Using an expert-ranked set of decision criteria, this comparative study aided in selecting the most suitable methodologies for the complex sustainable housing affordability assessment model. It was determined that COPRAS exhibited the highest potential in sustainable housing affordability decision analysis, but in a case of higher level uncertainty in criteria importance, TOPSIS, WSM and WPM can also be considered for their better tolerance to the higher level of the criterion weight change.

References[1] Communities and Local Government. Planning Policy Statement 3 (PPS3): Housing. London: The Stationary Office; 2011.[2] Pollard T. Jobs, Transportation, and Affordable Housing: Connecting Home and Work, Southern Environmental Law Center; 2010. Available at: https://www.southernenvironment.org/uploads/publications/connecting_home_and_work.pdf [Accessed 24 February 2014].

[3] Talen E, Koschinsky J. Is subsidized housing in sustainable neighborhoods? Evidence from Chicago. Housing Policy Debate 2011; 21:1-28.

[4] Australian Conservation Foundation and Victorian Council of Social Service. Housing affordability: More than rents and mortgages: 2008. Available at: 
vcoss.org.au/documents/VCOSS\%20docs/Housing/REP_ACF_VCOSS\%20Housing\%20Affordabi lity\%200ctober\%202008\%20.PDF [Accessed 18 February 2014].

[5] Mulliner E, Maliene V. Affordable Housing Policy and Practice in the UK. In: Hepperle E, Dixon-Gough R, Maliene V, Mansberger R, Paulsson J, Pödör A, editors. Land Management: Potential, Problems and Stumbling Blocks. Zürich, Switzerland: Vdf Hochschulverlag; 2012, 267277.

[6] Mulliner E, Maliene V. An Analysis of Professional Perceptions of Criteria Contributing to Sustainable Housing Affordability. Sustainability 2015; 7:248-270.

[7] Gan Q, Hill RJ. Measuring housing affordability: Looking beyond the median. Journal of Housing economics 2009; 18:115-125.

[8] Jones C, Watkins C, Watkins D. Measuring local affordability: variations between housing market areas. International Journal of Housing Markets and Analysis 2011;4:341-356.

[9] Nepal B, Tanton R, Harding A. Measuring Housing Stress: How Much do Definitions Matter? Urban Policy and Research 2010;28:211-224.

[10] Whitehead C, Monk S, Clarke A, Holmans A, Markkanen S. Measuring Housing Affordability: A Review of Data Sources. Cambridge: Cambridge Centre for Housing and Planning Research; 2009.

[11] Fisher LM, Pollakowski HO, Zabel J. Amenity-Based Housing Affordability Indexes. Real Estate Economics 2009;37:705-746.

[12] Gabriel M, Jacobs K, Arthurson K, Burke T, Yates J. Conceptualising and measuring the housing affordability problem, Research Paper 1. Melbourne: Australian Housing and Urban Research Institute; 2005.

[13] Rowley S, Ong R. Housing affordability, housing stress and household wellbeing in Australia. Melbourne: Australian Housing and Urban Research Institute; 2012.

[14] Bramley G. An affordability crisis in British housing: dimensions, causes and policy impact. Housing Studies 1994; 9:103-124. 
[15] Chen J, Hao Q, Stephens M. Assessing Housing Affordability in Post-reform China: A Case Study of Shanghai. Housing Studies 2010; 25:877-90.

[16] Gurran N, Phibbs P. Housing supply and urban planning reform: the recent Australian experience, 2003-2012. International Journal of Housing Policy 2013; 13:381-407.

[17] Haffner M, Boumeester $H$. Is renting unaffordable in the Netherlands. International Journal of Housing Policy 2014; 14:117-140.

[18] Hulchanski JD. The concept of housing affordability: Six contemporary uses of the housing expenditure-to-income ratio. Housing Studies 1995; 10:471-491.

[19] MacLennan D, Williams R. Affordable housing in Britain and America. York: Joseph Rowntree Foundation; 1990.

[20] Whitehead C. From need to affordability: an analysis of UK housing objectives. Urban Studies 1991; 28:871-887.

[21] Stone ME. What Is Housing Affordability? The Case for the Residual Income Approach. Housing Policy Debate 2006; 17:151-183.

[22] Belsky ES, Goodman J, Drew R. Measuring the Nation's Rental Housing Affordability Problems. Cambridge, MA: Joint Center for Housing Studies; 2005.

[23] Bogdon AS, Can A. Indicators of Local Housing Affordability: Comparative and Spatial Approaches. Real Estate Economics 1997; 25:43-80.

[24] Mattingly K, Morrissey J. Housing and transport expenditure: Socio-spatial indicators of affordability in Auckland. Cities 2014; 38:69-83.

[25] Stone ME, Burke T, Ralston L. The Residual Income Approach to Housing Affordability: The Theory and the Practice, Positioning Paper No. 139. Melbourne, Australia: Australian Housing and Urban Research Institute; 2011.

[26] Haffner M, Heylen K. User costs and housing expenses. Towards a more comprehensive approach to affordability. Housing Studies 2011; 26:593-614. 
[27] McCord M, McGreal S, Berry J, Haran M, Davis P. The implications of mortgage finance on housing market affordability. International Journal of Housing Markets and Analysis 2011; $4: 394-417$

[28] Maliene V, Howe J, Malys N. Sustainable communities: affordable housing and socioeconomic relations. Local Economy 2008; 23:267-276.

[29] Maliene V, Malys N. High-quality housing - a key issue in delivering sustainable communities. Building and Environment 2009; 44:426-430.

[30] Mulliner E, Smallbone K, Maliene V. An Assessment of sustainable housing affordability using a multiple criteria decision making method. Omega 2013; 41:270-279.

[31] Hall P, Tewdwr-Jones M. Urban and Regional Planning. 5th ed. Oxon: Routledge; 2011.

[32] Triantaphyllou E. Multi-Criteria Decision Making Methods: A Comparative Study. Dordrecht: Kluwer Academic Publishers; 2000.

[33] Zavadskas EK, Turskis Z, Kildienė S. State of art surveys of overviews on MCDM/MADM. Technological and Economic Development of Economy 2014; 20:165-179.

[34] Liou JJH, Tzeng GH. Comments on "Multiple criteria decision making (MCDM) methods in economics: an overview". Technological and Economic Development of Economy 2012; 18:672695.

[35] Roy B. Multicriteria Methodology for Decision Aiding. Dordrecht: Kluwer Academic Publishers; 1996.

[36] Zavadskas EK, Turskis Z. Multiple criteria decision making (MCDM) methods in economics: an overview. Technological and Economic Development of Economy 2011; 17:397-427.

[37] Adler N, Friedman L, Sinuany-Stern Z. Review of ranking methods in the data envelopment analysis context. European Journal of Operational Research 2002; 140:249-265.

[38] Maliene V. Valuation of commercial premises using a multiple criteria decision-making method. International Journal of Strategic Property Management 2001; 5:87-98.

[39] Maliene V. Specialised property valuation: Multiple criteria decision analysis. Journal of Retail and Leisure Property 2011; 9:443-450. 
[40] Maliene V, Zavadskas EK, Kaklauskas A, Raslanas S. Real estate valuation by multicriteria approach. Journal of Civil Engineering and Management 1999; 5: 272-284.

[41] Opricovic S, Tzeng GH. Compromise solution by MCDM methods: a comparative analysis of VIKOR and TOPSIS. European Journal of Operational Research 2004; 156:444-5.

[42] Peng Y, Kou G, Wang G, Shi Y. FAMCDM: A Fusion Approach of MCDM Methods to Rank Multiclass Classification Algorithms. Omega 2011; 39:677-689.

[43] Tavares LV. An acyclic outranking model to support group decision making within organizations. Omega 2012; 40:782-790.

[44] Zavadskas EK, Kaklauskas A, Maliene V. Real estate price evaluation by means of multicriteria project assessment methods. In: Zavadskas E, Sloan B, Kaklauskas A, editors. Real estate valuation and investment in central and eastern Europe during the transition to free market economy. Vilnius: Technika; 1997, 156-170.

[45] Hwang C, Yoon K. Multiple Attribute Decision Making. Berlin: Springer; 1981.

[46] Belton V. A comparison of the analytic hierarchy process and a simple multi- attribute value function. European Journal of Operational Research 1986; 26:7-21.

[47] Zanakis SH, Solomon A, Wishart N, Dublish S. Multi-attribute decision making: a simulation comparison of select methods. European Journal of Operations Research 1998;107:507-529.

[48] Keeney R, Raiffa H. Decisions with Multiple Objectives. New York: Wiley; 1976.

[49] Roy B. The outranking approach and the foundations of the ELECTRE methods. Theory and Decision 1991; 31:49-73.

[50] Brans JP, Vincke P. A Preference Ranking Organisation Method (The PROMETHEE Method for Multiple Criteria Decision Making). Management Science 1985; 31:647-656.

[51] Wang JJ, Jing YY, Zhang CF, Zhao JH. Review on multi-criteria decision analysis aid in sustainable energy decision-making. Renewable and Sustainable Energy Reviews 2009; $13: 2263-2278$

[52] Ball J, Srinivasan V. Using the Analytic Hierarchy Process in House Selection. Real Estate Finance and Economics 1994; 9:69-85. 
[53] Bender A, Din A, Hoesli M, Brocher S. Environmental preferences of homeowners: Further evidence using the AHP method. Journal of Property Investment and Finance 2000; 18: 445-455. [54] Kauko T. An analysis of housing location attributes in the inner city of Budapest, Hungary, using expert judgements. International Journal of Strategic Property Management 2007; 11:209-225.

[55] Lotfi S, Solaimani K. An assessment of Urban Quality of Life by Using Analytic Hierarchy Process Approach (Case study: Comparative Study of Quality of Life in the North of Iran). Social Sciences 2009; 5:123-133.

[56] Zavadskas EK, Kaklauskas A, Banaitis A, Kvederyte N. Housing credit access model: The case for Lithuania. European Journal of Operational Research 2004; 155:335-352.

[57] Viteikienè M. Zavadskas EK. Evaluating the sustainability of Vilnius City residential areas. Civil Engineering and Management 2007; 13:149-155.

[58] Kaklauskas A, Zavadskas EK, Banaitis A, Satkauskas, G. Defining the utility and market value of a real estate: A multiple criteria approach. International Journal of Strategic Property Management 2007; 11:107-120.

[59] Marinoni O. A discussion on the computational limitations of outranking methods for landuse suitability assessment. International Journal of Geographical Information Science 2006; 20:69-87.

[60] Vilutienè T, Zavadskas EK. The application of multi-criteria analysis to decision support for the facility management of a city's residential district. Journal of Civil Engineering and Management 2003; 10:241-252.

[61] Natividade-Jesus E, Coutinho-Rodrigues J, Antunes CH. A multicriteria decision support system for housing evaluation. Decision Support Systems 2007; 43: 779-790.

[62] Medineckienè M, Turskis Z, Zavadskas EK, Tamošaitienė J. Multi-Criteria Selection of the One Flat Dwelling House, Taking into Account the Construction Impact on Environment. Proceedings of the 10th International Conference Modern Building Materials, Structures and Techniques. Lithuania, Vilnius; May 19-21, 2010, 455-460. 
[63] Mulliner E, Maliene V. What Attributes Determine Housing Affordability? World Academy of Science, Engineering and Technology 2012; 67:695-700.

[64] Guitouni A, Martel JM. Tentative Guidelines to Help Choosing an Appropriate MCDA Method. European Journal of Operational Research 1998; 109:501-521.

[65] Roy B, Słowinski R. Questions guiding the choice of a multicriteria decision aiding method. EURO Journal on Decision Processes 2013; 1:69-97.

[66] Banaitienè N, Banaitis A, Kaklauskas A, Zavadskas EK. Evaluating the life cycle of a building: A multivariant and multiple criteria approach. Omega 2008; 36:429-441.

[67] Chang YH, Yeh CH. Evaluating airline competitiveness using multiattribute decision making. Omega 2001; 29:405-415.

[68] Mahmoud MR, Garcia LA. Comparison of different multicriteria evaluation methods for the Red Bluff diversion dam. Environmental Modelling and Software 2000; 15: 471-478.

[69] Hajkowicz SA, Higgins A. A Comparison of Multiple Criteria Analysis Techniques for Water Resource Management. European Journal of Operational Research 2008; 184:225-265.

[70] Fishburn PC. Additive utilities with incomplete product set: applications to priorities and assignments. Baltimore, MD: Operations Research Society of America (ORSA); 1967.

[71] Bridgman PW. Dimensional analysis. New Haven, CN: Yale University Process; 1992.

[72] Miller DW, Starr MK. Executive Decisions and Operations Research. Englewood Cliffs, NJ: Prentice-Hall; 1969.

[73] Triantaphyllou E, Mann SH. An examination of the effectiveness of multi-dimensional decision-making methods: A decision-making paradox. Decision Support Systems 1989; 5:303312.

[74] Belton V, Stewart TJ. Multiple criteria decision analysis: an integrated approach. Boston: Kluwer Academic Publications; 2002.

[75] Belton V, Gear T. On a short-coming of Saaty's method of analytic hierarchies. Omega 1983; $11: 228-230$. 
[76] Saaty TL. Fundamentals of Decision-Making and Priority Theory with the AHP. Pittsburg: RWS Publications; 1994.

[77] Millet I, Schoner B. Incorporating negative values into the Analytic Hierarchy Process. Computers and Operations Research 2005; 32:3163-3173.

[78] Zavadskas EK, Kaklauskas A, Sarka V. The new method of multicriteria complex proportional assessment of projects. Technological and Economic Development of Economy $1994 ; 1: 131-139$.

[79] Chen SJ, Hwang CL. Fuzzy Multiple Attribute Decision Making: Methods and Applications. Berlin: Springer-Verlag; 1992.

[80] Ginevičius R, Podvezko V. Evaluating the changes in economic and social development of Lithuanian counties by multiple criteria methods. Technological and Economic Development of Economy 2009; 15:418-36.

[81] Rao RV. Decision Making in Manufacturing Environment Using Graph Theory and Fuzzy Multiple Attribute Decision Making Methods (Springer Series in Advanced Manufacturing). London: Springer; 2013, 205-242.

[82] Dyer JS, Fishburn PC, Steuer RE, Wallenius J, Zionts S. Multiple criteria decision making, multiattribute utility theory: the next ten years. Management Science 1992; 38: 645-654.

[83] Chatterjee P, Athawale VM, Chakraborty S. Materials selection using complex proportional assessment and evaluation of mixed data methods. Materials and Design 2011; 32:851-860.

[84] Simanaviciene R, Ustinovicius L. A New Approach to Assessing the Biases of Decisions based on Multiple Attribute Decision making Methods. Elektronika ir Elektrotechnika 2012; 117:29-32. 


\section{Figure legends}

Figure 1. Liverpool housing wards used for comparison purpose in this study. Alternative numbers are provided in the brackets. Ranking of housing wardsfor sustainable housing affordability is highlighted with different colour circles, green (high), yellow (medium) and red (low).

Figure 2. Sensitivity analysis of how the change in criterion weight affect ranking of alternatives. Dark green rectangles indicate the tolerable change of criteria weight (as shown in the top panel), to which the alternative ranking is not sensible, while light green rectangles represent the range that contributes to the single change of alternatives. Abbreviations of criteria are shown on the left side of panel. Results for six MSDM methods in each criterion panel are displayed in the following order: WSM (top), WPM, revised AHP 1, revised AHP 2, TOPSIS and COPRAS (bottom).

Figure 3. Diagram of sensitivity coefficients for each criterion. Multiple bars for each criterion show sensitivity coefficients calculated for all six MCDM methods allowing for $-5 \%,-50 \%,+5 \%$, and $+50 \%$ changes of the criterion weight.

Figure 4. Most critical criteria for any and best alternatives. Bar chart compares sensitivity coefficients of most critical criteria established using different MCDM models. 


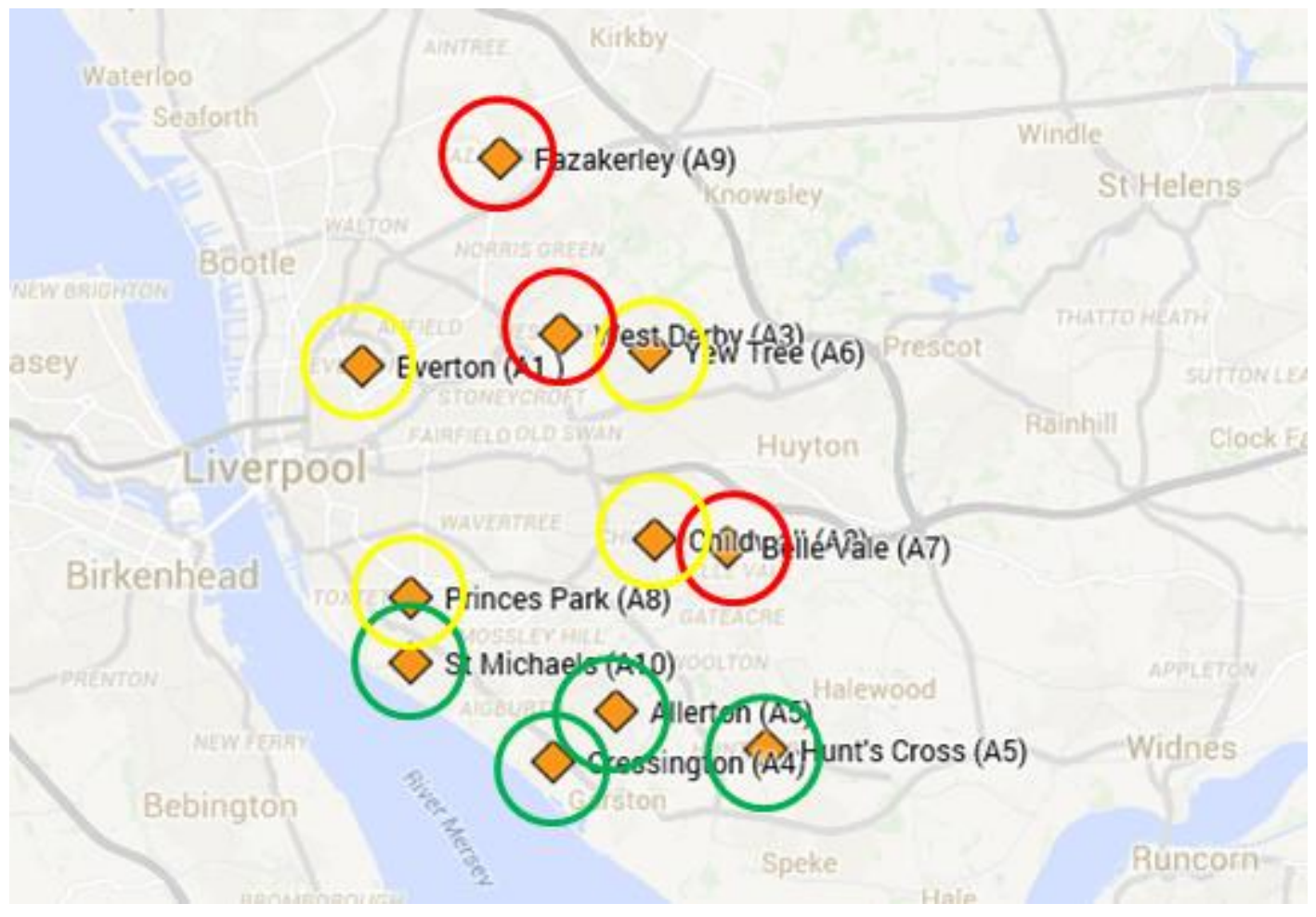

Figure 1 


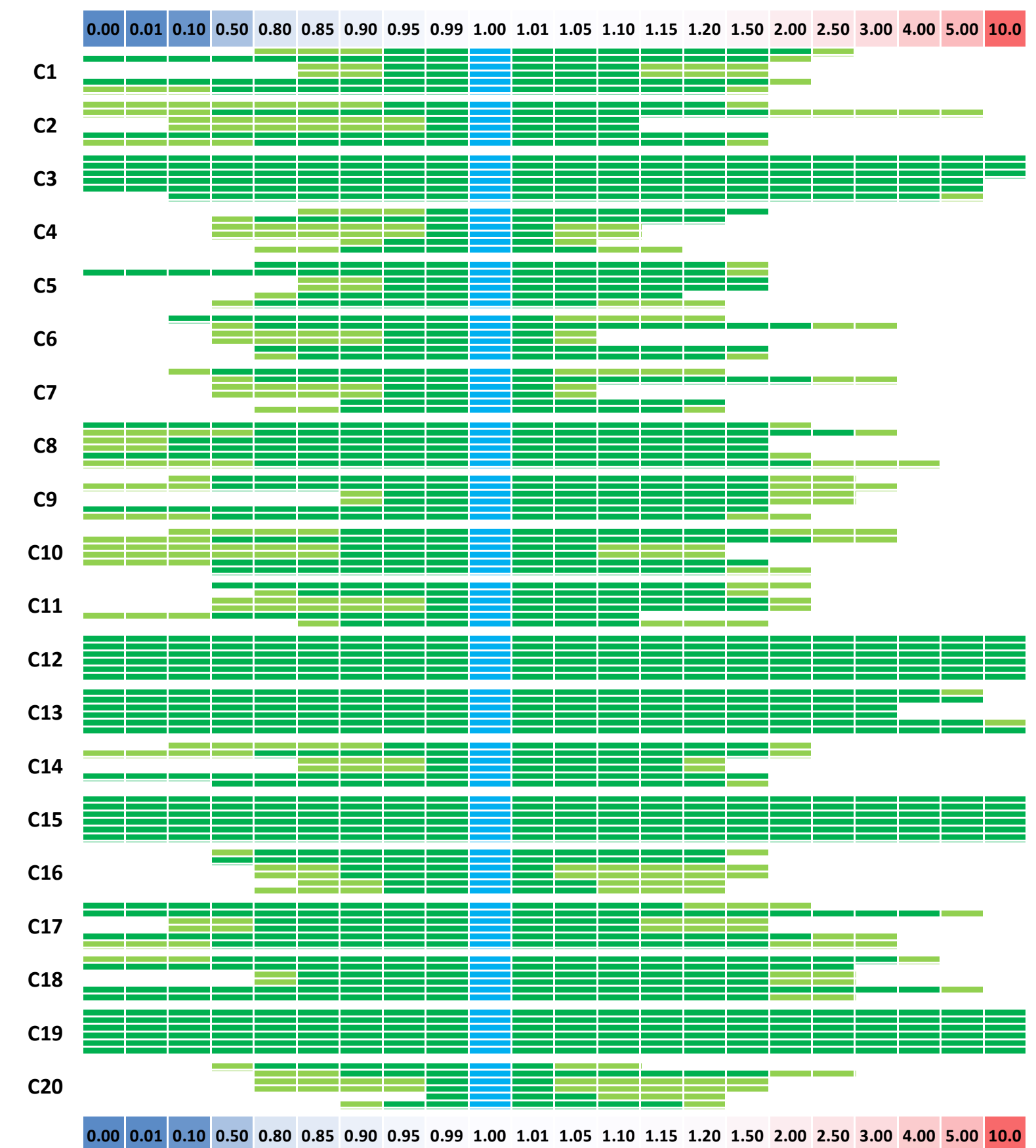

Figure 2 


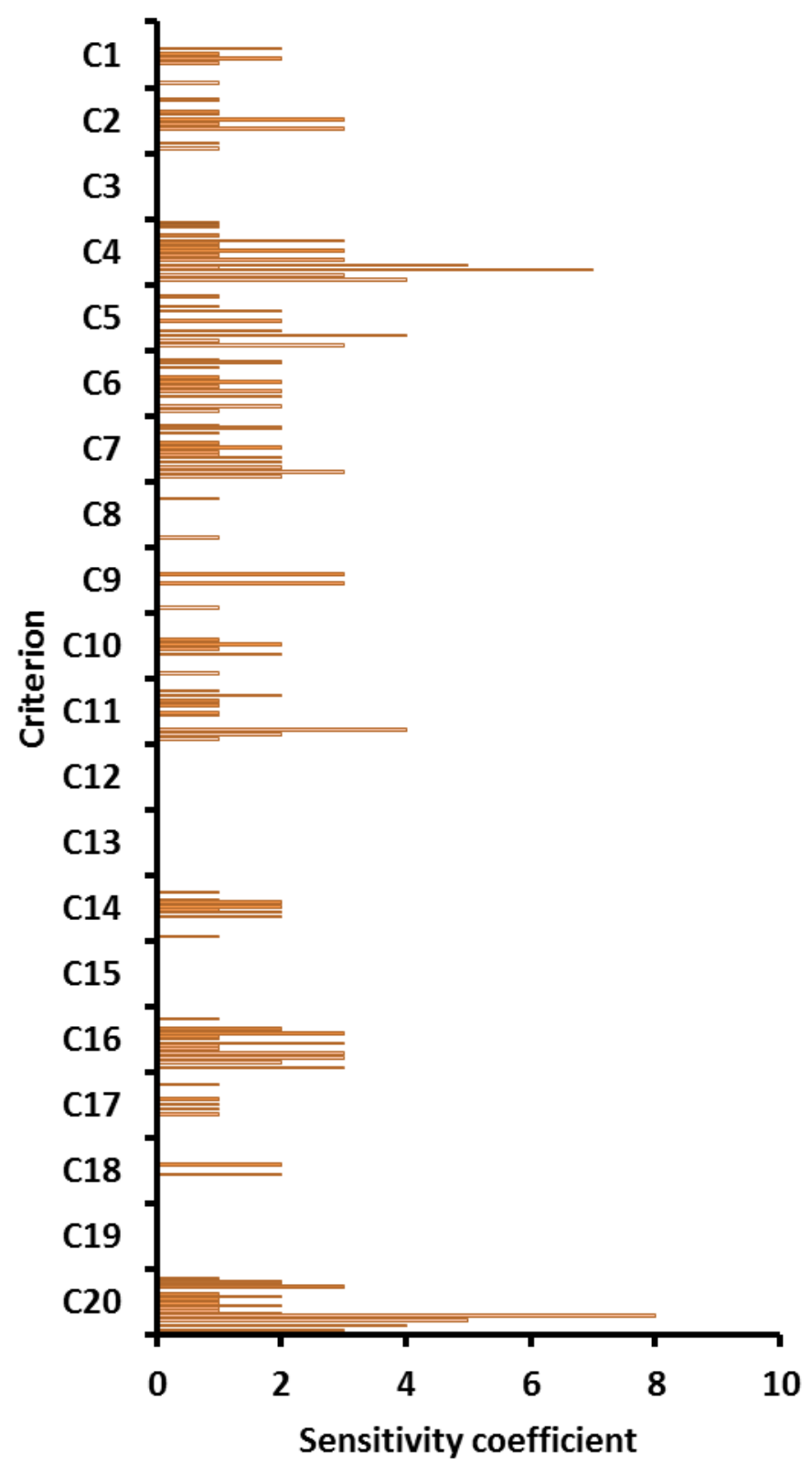

Figure 3 


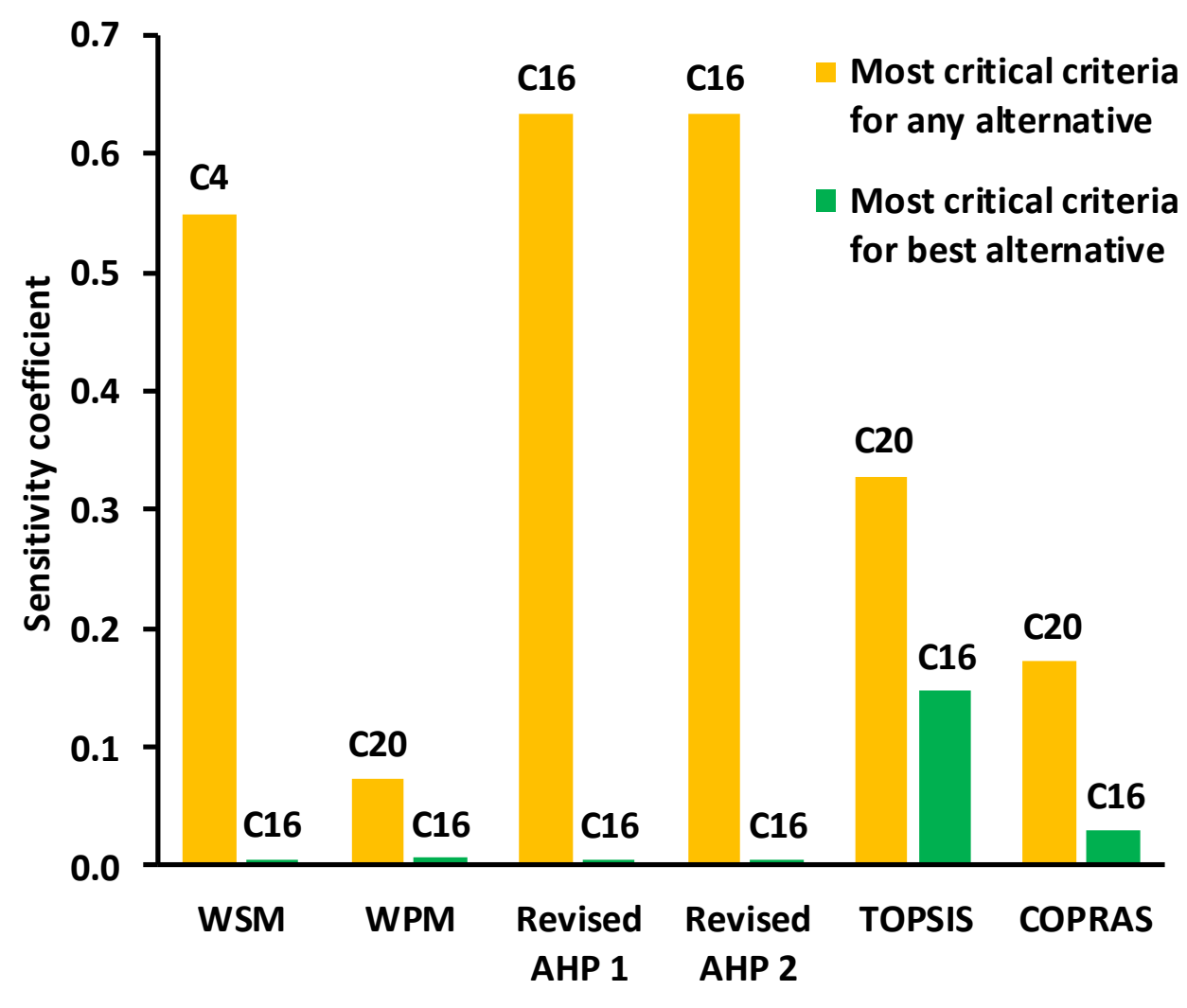

Figure 4 
Table 1. Initial matrix for MCDM

\begin{tabular}{|c|c|c|c|c|c|c|c|c|c|c|c|c|c|c|}
\hline \multirow{2}{*}{\multicolumn{2}{|c|}{ Criteria $i$}} & \multirow{2}{*}{$z$} & \multirow{2}{*}{$\begin{array}{c}\text { Measur } \\
\text { ement }\end{array}$} & \multirow{2}{*}{ Weight } & \multicolumn{10}{|c|}{ Alternatives $j$} \\
\hline & & & & & $A_{1}$ & $A_{2}$ & $A_{3}$ & $A_{4}$ & $A_{5}$ & $A_{6}$ & $A_{7}$ & $A_{8}$ & $A_{9}$ & $A_{10}$ \\
\hline 1 & House prices in relation to income & - & Ratio & 0.063135 & 3.5 & 4.9 & 4.7 & 4.9 & 5.1 & 4 & 4.8 & 3.6 & 3.8 & 4.7 \\
\hline 2 & Rental costs in relation to income & - & $\%$ & 0.063135 & 19 & 30 & 24 & 28 & 28 & 24 & 29 & 30 & 23 & 25 \\
\hline 3 & $\begin{array}{c}\text { Interest rates and mortgage } \\
\text { availability }\end{array}$ & - & $\%$ & 0.058055 & 60 & 60 & 60 & 60 & 60 & 60 & 60 & 60 & 60 & 60 \\
\hline 4 & Availability of rented accommodation & + & $\%$ & 0.058055 & 1.3 & 0.4 & 0.32 & 0.82 & 0.3 & 0.6 & 0.1 & 1.1 & 0.7 & 1.4 \\
\hline 5 & $\begin{array}{c}\text { Availability of low cost } \\
\text { homeownership products }\end{array}$ & + & Points & 0.051524 & 2 & 1 & 1 & 1 & 2 & 2 & 3 & 3 & 1 & 2 \\
\hline 6 & $\begin{array}{l}\text { Availability of market value home } \\
\text { ownership products }\end{array}$ & + & $\%$ & 0.04717 & 1.1 & 2.8 & 2.3 & 2.7 & 2.7 & 2.5 & 1.3 & 1.1 & 2.3 & 3 \\
\hline 7 & Crime & - & Rate & 0.044267 & 135 & 39 & 58 & 41 & 57 & 56 & 65 & 135 & 89 & 75 \\
\hline 8 & Access to employment & + & Points & 0.053701 & 3 & 3 & 3 & 3 & 3 & 2 & 3 & 3 & 3 & 3 \\
\hline 9 & Access to public transport & + & Points & 0.049347 & 4 & 3 & 4 & 5 & 4 & 4 & 4 & 5 & 5 & 6 \\
\hline 10 & Access to good quality schools & + & Points & 0.050073 & 5 & 6 & 5 & 5 & 4 & 4 & 3 & 5 & 6 & 6 \\
\hline 11 & Access to shopping facilities & + & Points & 0.045718 & 3 & 1 & 2 & 2 & 3 & 1 & 2 & 3 & 1 & 3 \\
\hline 12 & Access to health services & + & Points & 0.047896 & 9 & 9 & 9 & 9 & 9 & 9 & 9 & 9 & 9 & 9 \\
\hline 13 & Access to child care & + & Points & 0.046444 & 6 & 6 & 6 & 5 & 6 & 6 & 6 & 6 & 6 & 6 \\
\hline 14 & Access to leisure & + & Points & 0.039913 & 6 & 3 & 5 & 5 & 4 & 5 & 4 & 5 & 4 & 4 \\
\hline 15 & Access to open green public space & + & Points & 0.043541 & 3 & 3 & 3 & 3 & 3 & 3 & 3 & 3 & 3 & 3 \\
\hline 16 & Presence of environmental problems & - & $\%$ & 0.044267 & 24 & 1.5 & 29.3 & 4 & 21.1 & 19.4 & 15.9 & 13 & 46.6 & 30.5 \\
\hline 17 & Quality of housing in area & + & $\%$ & 0.055152 & 72.4 & 70.3 & 69.1 & 79.4 & 86.2 & 89.9 & 77.5 & 72.8 & 89.1 & 82.9 \\
\hline 18 & Energy efficiency of housing in area & + & $\%$ & 0.05225 & 60 & 55 & 57 & 53 & 57 & 64 & 63 & 66 & 61 & 68 \\
\hline 19 & Waste management in area & + & $\%$ & 0.04209 & 35 & 35 & 35 & 35 & 35 & 35 & 35 & 35 & 35 & 35 \\
\hline 20 & Deprivation in area & - & $\%$ & 0.044267 & 97.6 & 5 & 5.2 & 3.1 & 0 & 38.8 & 83.5 & 93.7 & 62.1 & 22.1 \\
\hline
\end{tabular}

* The sign (+/-) indicates that a greater/lesser criterion value satisfies sustainable housing affordability 
Table 2. Initial matrix for MCDM with all criteria calculated as benefit criteria

\begin{tabular}{|c|c|c|c|c|c|c|c|c|c|c|c|c|c|}
\hline \multirow{2}{*}{\multicolumn{2}{|c|}{ Criteria $i$}} & \multirow{2}{*}{$\mathrm{Z}$} & \multirow{2}{*}{ Weight } & \multicolumn{10}{|c|}{ Alternatives $j$} \\
\hline & & & & 1 & 2 & 3 & 4 & 5 & 6 & 7 & 8 & 9 & 10 \\
\hline 1 & $\begin{array}{l}\text { House prices in relation to } \\
\text { incomes }\end{array}$ & + & 0.063135 & 5.1 & 3.7 & 3.9 & 3.7 & 3.5 & 4.6 & 3.8 & 5 & 4.8 & 3.9 \\
\hline 2 & $\begin{array}{l}\text { Rental costs in relation to } \\
\text { incomes }\end{array}$ & + & 0.063135 & 30 & 19 & 25 & 21 & 21 & 25 & 20 & 19 & 26 & 24 \\
\hline 3 & $\begin{array}{c}\text { Interest rates and mortgage } \\
\text { availability }\end{array}$ & + & 0.058055 & 60 & 60 & 60 & 60 & 60 & 60 & 60 & 60 & 60 & 60 \\
\hline 4 & $\begin{array}{l}\text { Availability of rented } \\
\text { accommodation }\end{array}$ & + & 0.058055 & 1.3 & 0.4 & 0.32 & 0.82 & 0.3 & 0.6 & 0.1 & 1.1 & 0.7 & 1.4 \\
\hline 5 & $\begin{array}{c}\text { Availability of low cost } \\
\text { homeownership products }\end{array}$ & + & 0.051524 & 2 & 1 & 1 & 1 & 2 & 2 & 3 & 3 & 1 & 2 \\
\hline 6 & $\begin{array}{c}\text { Availability of market value home } \\
\text { ownership products }\end{array}$ & + & 0.04717 & 1.1 & 2.8 & 2.3 & 2.7 & 2.7 & 2.5 & 1.3 & 1.1 & 2.3 & 3 \\
\hline 7 & Crime & + & 0.044267 & 39 & 135 & 116 & 133 & 117 & 118 & 109 & 39 & 85 & 99 \\
\hline 8 & Access to employment & + & 0.053701 & 3 & 3 & 3 & 3 & 3 & 2 & 3 & 3 & 3 & 3 \\
\hline 9 & Access to public transport & + & 0.049347 & 4 & 3 & 4 & 5 & 4 & 4 & 4 & 5 & 5 & 6 \\
\hline 10 & Access to good quality schools & + & 0.050073 & 5 & 6 & 5 & 5 & 4 & 4 & 3 & 5 & 6 & 6 \\
\hline 11 & Access to shopping facilities & + & 0.045718 & 3 & 1 & 2 & 2 & 3 & 1 & 2 & 3 & 1 & 3 \\
\hline 12 & Access to health services & + & 0.047896 & 9 & 9 & 9 & 9 & 9 & 9 & 9 & 9 & 9 & 9 \\
\hline 13 & Access to child care & + & 0.046444 & 6 & 6 & 6 & 5 & 6 & 6 & 6 & 6 & 6 & 6 \\
\hline 14 & Access to leisure & + & 0.039913 & 6 & 3 & 5 & 5 & 4 & 5 & 4 & 5 & 4 & 4 \\
\hline 15 & Access to open green public space & + & 0.043541 & 3 & 3 & 3 & 3 & 3 & 3 & 3 & 3 & 3 & 3 \\
\hline 16 & $\begin{array}{c}\text { Presence of environmental } \\
\text { problems }\end{array}$ & + & 0.044267 & 24.1 & 46.6 & 18.8 & 44.1 & 27 & 28.7 & 32.2 & 35.1 & 1.5 & 17.6 \\
\hline 17 & Quality of housing in area & + & 0.055152 & 72.4 & 70.3 & 69.1 & 79.4 & 86.2 & 89.9 & 77.5 & 72.8 & 89.1 & 82.9 \\
\hline 18 & $\begin{array}{c}\text { Energy efficiency of housing in } \\
\text { area }\end{array}$ & + & 0.05225 & 60 & 55 & 57 & 53 & 57 & 64 & 63 & 66 & 61 & 68 \\
\hline 19 & Waste management in area & + & 0.04209 & 35 & 35 & 35 & 35 & 35 & 35 & 35 & 35 & 35 & 35 \\
\hline 20 & Deprivation in area & + & 0.044267 & 0 & 92.6 & 92.4 & 94.5 & 97.6 & 58.8 & 14.1 & 3.9 & 35.5 & 75.5 \\
\hline
\end{tabular}


Table 31. Data obtained by ranking of the alternatives using different MCDM methods

\begin{tabular}{|c|c|c|c|c|c|c|c|c|c|c|}
\hline \multirow{2}{*}{ Method } & \multicolumn{10}{|c|}{ Alternatives } \\
\hline & $A_{1}$ & $A_{2}$ & $A_{3}$ & $A_{4}$ & $A_{5}$ & $A_{6}$ & $A_{7}$ & $A_{8}$ & $A_{9}$ & $A_{10}$ \\
\hline \multirow{2}{*}{ WSM rank } & 0.1015 & 0.0972 & 0.0962 & 0.1055 & 0.1013 & 0.0989 & 0.0903 & 0.1024 & 0.0932 & 0.1134 \\
\hline & 4 & 7 & 8 & 2 & 5 & 6 & 10 & 3 & 9 & 1 \\
\hline \multirow{2}{*}{ WPM rank } & 0 & 0.0923 & 0.0932 & 0.1029 & 0.0981 & 0.0972 & 0.0811 & 0.0905 & 0.0835 & 0.1105 \\
\hline & 10 & 6 & 5 & 2 & 3 & 4 & 9 & 7 & 8 & 1 \\
\hline \multirow{2}{*}{$\begin{array}{c}\text { Revised AHP } 1 \\
\text { rank }\end{array}$} & 0.81 & 0.7812 & 0.7816 & 0.832 & 0.8121 & 0.7937 & 0.7407 & 0.8131 & 0.7682 & 0.8884 \\
\hline & 5 & 8 & 7 & 2 & 4 & 6 & 10 & 3 & 9 & 1 \\
\hline \multirow{2}{*}{$\begin{array}{c}\text { Revised AHP } 2 \\
\text { rank }\end{array}$} & 0.9222 & 0.8434 & 0.8445 & 0.9824 & 0.9278 & 0.8775 & 0.7326 & 0.9308 & 0.8079 & 1.1365 \\
\hline & 5 & 8 & 7 & 2 & 4 & 6 & 10 & 3 & 9 & 1 \\
\hline \multirow{2}{*}{ TOPSIS rank } & 0.4713 & 0.629 & 0.4889 & 0.7909 & 0.6148 & 0.5445 & 0.299 & 0.5271 & 0.252 & 0.8092 \\
\hline & 8 & 3 & 7 & 2 & 4 & 5 & 9 & 6 & 10 & 1 \\
\hline \multirow{2}{*}{ COPRAS rank } & 0.099 & 0.1015 & 0.0961 & 0.1096 & 0.1021 & 0.0982 & 0.0891 & 0.1009 & 0.0912 & 0.1123 \\
\hline & 6 & 4 & 8 & 2 & 3 & 7 & 10 & 5 & 9 & 1 \\
\hline
\end{tabular}


Table 42. Priority of alternatives determined using different MCDM methods

\begin{tabular}{|c|c|c|c|c|c|}
\hline \multirow{2}{*}{$\begin{array}{c}\text { Priority of } \\
\text { alternatives }\end{array}$} & WSM & WPM & $\begin{array}{c}\text { Revised AHP } \\
\text { (approaches 1 } \\
\text { and 2) }\end{array}$ & TOPSIS & COPRAS \\
\cline { 2 - 6 } & $A_{10}$ & $A_{10}$ & $A_{10}$ & $A_{10}$ & $A_{10}$ \\
\hline 1 & $A_{4}$ & $A_{4}$ & $A_{4}$ & $A_{4}$ & $A_{4}$ \\
\hline 2 & $A_{8}$ & $A_{5}$ & $A_{8}$ & $A_{2}$ & $A_{5}$ \\
\hline 3 & $A_{1}$ & $A_{6}$ & $A_{5}$ & $A_{5}$ & $A_{2}$ \\
\hline 4 & $A_{5}$ & $A_{3}$ & $A_{1}$ & $A_{6}$ & $A_{8}$ \\
\hline 5 & $A_{6}$ & $A_{2}$ & $A_{6}$ & $A_{8}$ & $A_{1}$ \\
\hline 6 & $A_{2}$ & $A_{8}$ & $A_{3}$ & $A_{3}$ & $A_{6}$ \\
\hline 7 & $A_{3}$ & $A_{9}$ & $A_{2}$ & $A_{1}$ & $A_{3}$ \\
\hline 8 & $A_{9}$ & $A_{7}$ & $A_{9}$ & $A_{7}$ & $A_{9}$ \\
\hline 9 & $A_{7}$ & $A_{1}$ & $A_{7}$ & $A_{9}$ & $A_{7}$ \\
\hline 10 & & & & & \\
\hline
\end{tabular}


Table 5. Correlation between alternative rankings computed using different MCDM methods.

\begin{tabular}{|c|c|c|c|c|c|}
\hline Methods & WSM & WPM & $\begin{array}{c}\text { Revised AHP } \\
1 / 2\end{array}$ & TOPSIS & COPRAS \\
\hline WSM & 1.000 & .179 & .995 & .860 & .944 \\
\hline WPM & .179 & 1.000 & .189 & .389 & .306 \\
\hline Revised AHP 1 & .995 & .189 & 1.000 & .831 & .925 \\
\hline Revised AHP 2 & .995 & .189 & 1.000 & .831 & .925 \\
\hline TOPSIS & .860 & .389 & .831 & 1.000 & .969 \\
\hline COPRAS & .944 & .306 & .925 & .969 & 1.000 \\
\hline
\end{tabular}

$\begin{array}{lllllllllll}1 & 0.9 & 0.8 & 0.7 & 0.6 & 0.5 & 0.4 & 0.3 & 0.2 & 0.1 & 0\end{array}$

Similarity matrix is represented as a heat-map (shown below table 5) that shows the level of correlation between ranking results. The colour red indicates the most dissimilar rankings. MCDM method pairs with absolutely equal rankings has a Pearson correlation value equal to "1" and are indicated in the colour green. 
Table 6. Distribution of sensitivity coefficients $S C^{*}$ s.

\begin{tabular}{|c|c|c|c|c|c|c|c|c|c|c|c|c|}
\hline \multirow{5}{*}{$\begin{array}{l}\text { MCDM } \\
\text { method }\end{array}$} & \multicolumn{12}{|c|}{ Change of criterion weight } \\
\hline & \multicolumn{3}{|c|}{$-5 \%$} & \multicolumn{3}{|c|}{$+5 \%$} & \multicolumn{3}{|c|}{$-50 \%$} & \multicolumn{3}{|c|}{$+50 \%$} \\
\hline & \multicolumn{12}{|c|}{ Sensitivity coefficient SC* } \\
\hline & 0 & 1 & $>1$ & 0 & 1 & $>1$ & 0 & 1 & $>1$ & 0 & 1 & $>1$ \\
\hline & \multicolumn{12}{|c|}{ Occurance of sensitivity coefficient amongst 20 criteria } \\
\hline WSM & 19 & 1 & 0 & 17 & 3 & 0 & 12 & 5 & 3 & 12 & 5 & 3 \\
\hline WPM & 20 & 0 & 0 & 20 & 0 & 0 & 13 & 5 & 2 & 16 & 2 & 2 \\
\hline Revised AHP 1 & 15 & 5 & 0 & 15 & 5 & 0 & 6 & 7 & 7 & 10 & 4 & 6 \\
\hline Revised AHP 2 & 15 & 5 & 0 & 15 & 5 & 0 & 6 & 7 & 7 & 10 & 4 & 6 \\
\hline TOPSIS & 19 & 0 & 1 & 19 & 1 & 0 & 14 & 0 & 6 & 14 & 0 & 6 \\
\hline COPRAS & 20 & 0 & 0 & 20 & 0 & 0 & 11 & 3 & 6 & 8 & 7 & 5 \\
\hline
\end{tabular}

